\title{
КОНЦЕПТУАЛЬНЫЕ ПОДХОДЫ ФОРМИРОВАНИЯ СТРАТЕГИИ ОРГАНИЗАЦИИ В УСЛОВИЯХ НЕУСТОЙЧИВОГО СПРОСА
}

\author{
А.А. Кондратенко \\ Московский гуманитарный университет
}

\begin{abstract}
Аннотация: B статье определяется роль формирования стратегии и тактики иенообразования организации, действующей в условиях неустойчивого спроса. Представлена схема формирования стратегии и тактики ценообразования с использованием системного подхода формирования целей ценовой политики. Обозначены методы оиенки эффективности иеновой стратегии и уровня маркетинговой компетенции.

Ключевые слова: рынок, рыночный механизм, спрос, конкурентная среда, рыночная позиция, стратегия, тактика, цееновая стратегия, формирование изены, системный подход
\end{abstract}

\section{CONCEPTUAL APPROACHES TO THE FORMATION OF AN ORGANIZATION'S STRATEGY IN CONDITIONS OF UNSTABLE DEMAND}

\author{
A.A. Kondratenko \\ Moscow University for the Humanities
}

\begin{abstract}
Annotation: The role of forming the pricing strategy and tactics of an organization operating in conditions of unstable demand is determined. The scheme of formation of pricing strategy and tactics using a systematic approach to the formation of pricing policy goals is presented. Methods for evaluating the effectiveness of the pricing strategy and the level of marketing competence are outlined.

Keywords: market, market mechanism, demand, competitive environment, market position, strategy, tactics, price strategy, price formation, system approach
\end{abstract}

В современных условиях исследование реакции рынка на рыночную активность организаций способствует развитию рыночных отношений, делает их менее хаотичными и более предсказуемыми. Такие экономические категории как спрос, стратегия и тактика, ценовая политика относятся к рыночным отношениям. В свою очередь рынок является совокупностью отношений между субъектами, участвующими в обменных процессах.

Закон спроса говорит о том, что если цена на товар падает, объем его продаж увеличивается. В рамках классификации и исследования рынка следует выделить следующие типы спроса:

1) Эффективный спрос (реальный, фактический) - готовность приобрести продукт поддерживается наличием соответствующего эквивалента, т.е. суммы, фактически оплаченной потребителями. Эффективный спрос возникает в точке, где функция общего предложения становится равной функции общего спроса.

2) Потенциальный (виртуальный) спрос - это желание приобрести конкретный товар, не подкрепленное возможностями получения дохода, т.е. количеством товаров, которое покупатели хотели бы купить (Юрьев, 2016: 98). 
В случае улучшения ситуации с доходами покупателя потенциальный спрос может превратиться в платежеспособный спрос (Зборовская, 2016: 67).

Спрос также можно различать по типу товара, а именно: замещающий спрос, т.е. спрос на товары, которые заменяют друг друга, или дополнительный спрос, т.е. спрос на товары, дополняющие друг друга.

Таким образом, в рыночных условиях действует закон спроса и предложения, а анализ и оценка их гибкости могут быть эффективно использованы для формирования ценовой политики. Фактор эластичности будет одним из основных влияющих элементов стратегии организаций (Ковени, 2015: 172).

В условиях активизации конкурентной среды и глобализации мирового рынка организации вынуждены совершенствовать ценовую политику. Но сегодня процесс формирования цены требует существенного совершенствования. Это вызвано необходимостью более глубокого переосмысления подходов к формированию цены на продукцию современной организации.

В условиях рыночной экономики спрос является основным источником информации для принятия хозяйственных решений субъектами хозяйствования. На нынешнем этапе решения практических задач по вопросам формирования спроса должны основываться и быть нацелены на действенные теоретические подходы по эффективному ценообразованию субъектов хозяйствования в условиях рынка. Поэтому вопрос рыночного механизма формирования цен и ценовой политики, которая достигается воплощением продуманной ценовой стратегии и тактики ценообразования, является основным элементом стратегии маркетинга, имеет большой экономический интерес для всех участников рынка и государства.

Таким образом, процесс определения цены носит системный характер и раскрывает научное познание с помощью различных методов ценообразования, принципов и средств их достижения с целью получения запланированных и ожидаемых результатов. Исследование ценообразования целесообразно осуществлять с позиции маркетинга и менеджмента, что заложено в системный анализ ценообразования, поскольку только на этой основе можно повысить значимость этого процесса (Ковени, 2015: 174). Таким образом, можно отметить, что методика определения цены имеет системный характер и раскрывает научное познание с помощью комплекса методов ценообразования, принципов и средств их достижения.

Согласно предлагаемой схеме формирования стратегии и тактики ценообразования в маркетинге (рис. 1) наблюдаем, что при системном подходе формирования целей ценовой политики, выбор стратегии и тактики ценообразования являются компонентами стратегического маркетинга и составляют подсистему маркетинга. 
Научные труды Московского гуманитарного университета

2020 № 6

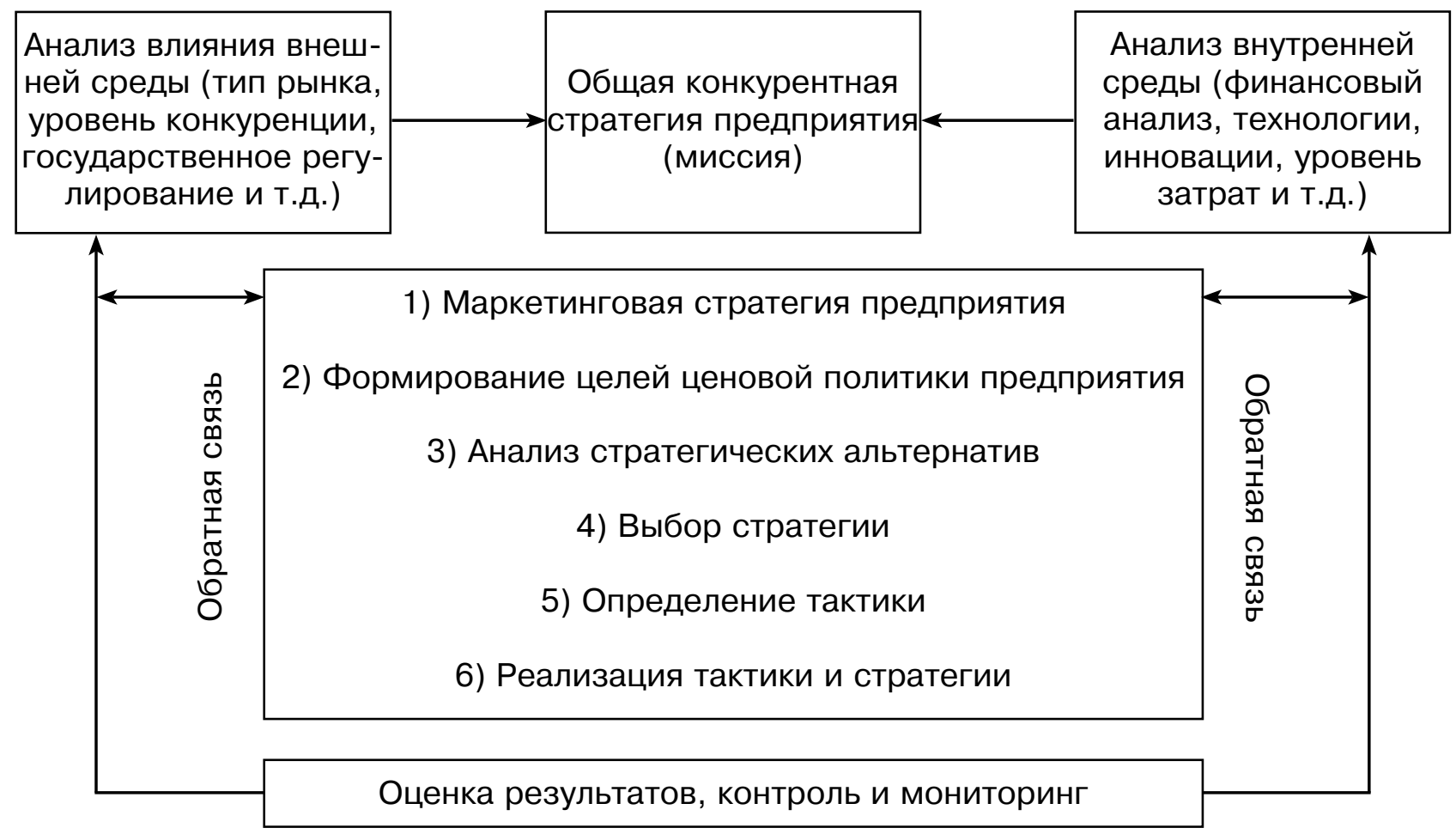

Рисунок 1. Схема проиесса формирования стратегии и тактики цеенообразования. Составлено по (Длигач, 2016: 86); (Коринев, Бокулева, Олейник, 2016: 104)

Общая конкурентная стратегия (миссия) организации при применении системного подхода выполняется преимущественно на «входе» системы (организации, компании и т.д.), а реализация тактики и стратегии в основном на «выходе». Благодаря обратной связи можно оценить результаты реализации тактики и стратегии ценообразования и повысить качество «входа» (подробный анализ внешней и внутренней среды организации).

В результате исследования наиболее распространенных видов ценовых стратегий (Длигач, 2016: 186) подтверждается утверждение, что ценовые стратегии являются средством достижения конкурентных стратегий организаций, а ценообразование составляет элемент маркетинга.

Ученые (особенно отечественные) большое внимание уделяют общим теоретическим аспектам цены, затрат, ценообразования, методам расчета цены вместо того, чтобы определить, как организации вести себя при неустойчивом спросе в долгосрочном периоде, какие решения принимать в краткосрочном периоде, чтобы обеспечить покрытие всех расходов и повысить свою конкурентоспособность.

При формировании стратегии ценообразования организации необходимо предусмотреть возможные ответные меры конкурентов, чтобы успеть перестроить тактику конкурентной борьбы в определенное время и в нужном направлении, что 
также возможно в результате снижения цены на конкурирующие товары, улучшения их потребительских свойств, использования эффективной рекламы и др.

Эффективность ценовой стратегии целесообразно оценить, сопоставляя полученный эффект и затраты на управление, а уровень маркетинговой компетенции экспертными оценками-

Выбирая тип стратегии предприятию следует определить, будет ли она проактивной (устанавливает целенаправленные действия), реактивной (предусматривает реакцию организации на непредвиденные изменения) или комплексной (объединяет оба типа).

Существенная функция политики ценообразования организации обеспечение его устойчивых конкурентных позиций, которые должны быть связанны со стратегическими целями организации и ориентированы на обеспечение его конкурентоспособности. Конкурентная позиция организации зависит от его рыночной позиции, эффективности управленческой деятельности и уровня маркетинговой компетенции.

Независимо от типа выбранная ценовая стратегия должна обеспечивать социальную и экономическую адаптацию организации. Конкурентные стратегии ценообразования разрабатывают на основе построения стратегической пирамиды, что предусматривает увязку корпоративной, деловой стратегии с функциональными и операционными стратегиями.

Итак, выбранная оптимальная ценовая стратегия при неустойчивом спросе не только влияет на общую стратегию организации, но и на ее выживание и на получение длительных конкурентных преимуществ с учетом их маркетинговых возможностей.

\section{СПИСОК ЛИТЕРАТУРЫ}

Длигач А.А. (2016) Стратегическое маркетинговое управление: Монография. М.: Алерта. 270 с.

Зборовская А.Н. (2016) Ценообразование как основа эффективности функционирования организаций и фактор повышения благосостояния населения: Монография. М.: Финансы и статистика. 289 с.

Ковени М. (2015) Стратегический разрыв. Технологии воплощения корпоративной стратегии в жизнь. - М.: Альпина Бизнес Букс. 232 с.

Коринев В.Л., Бокулева Н.А., Олейник И.В. (2016) Ценообразование на услуги: Монография. Краснодар: КПУ, 2016. 211 с.

Юрьев А.П., Ермилова К.В. (2016) Формирование цены и ценовой политики на предприятиях консалтингового бизнеса. М.: Логос. 200 с.

Кондратенко Алексей Алексеевич - обучающийся 3 курса образовательной программы магистратуры по направлению подготовки «Экономика предприятия» 
Московского гуманитарного университета. Научный руководитель - д.э.н., проф. Меньшикова О.И. Адрес: 111395, Россия, г. Москва, ул. Юности, д. 5. Тел.: +7 (499) 374-74-59. Эл. адрес: kafedra@mosgu.ru

Kondratenko Alexey Alekseevich is a 3rd-year student of the master's degree program in the field of enterprise Economics at Moscow state University for the Humanities. Scientific supervisor-doctor of Economics, prof. Menshikova O. I. Address: 5 Yunosti str., Moscow, 111395, Russia. Phone: +7 (499) 374-74-59. email: kafedra@mosgu.ru 